\title{
A Type of MOF-Derived Porous Carbon with Low Cost as an Efficient Catalyst for Phenol Hydroxylation
}

\author{
Renjie Zhou, ${ }^{1}$ Gui Chen $\mathbb{D}^{1,2}$ Yuejun Ouyang, ${ }^{1}$ Hairui Ni, ${ }^{1}$ Nonglin Zhou ${ }^{\mathbb{D}},{ }^{1}$ \\ and Bailin Xiang $\mathbb{B}^{1}$ \\ ${ }^{1}$ College of Chemistry and Materials Engineering, Huaihua University, Huaihua 418000, China \\ ${ }^{2}$ College of Chemistry Engineering, Xiangtan University, Xiangtan 411000, China \\ Correspondence should be addressed to Nonglin Zhou; 529085672@qq.com and Bailin Xiang; 10253007@qq.com
}

Received 20 July 2021; Revised 23 September 2021; Accepted 24 September 2021; Published 18 October 2021

Academic Editor: Jianqiang Liu

Copyright (C) 2021 Renjie Zhou et al. This is an open access article distributed under the Creative Commons Attribution License, which permits unrestricted use, distribution, and reproduction in any medium, provided the original work is properly cited.

Using MOF-5 as a template, the porous carbon (MDPC-600) possessing high specific surface area was obtained after carbonization and acid washing. After MDPC-600 was loaded with $\mathrm{Cu}$ ions, the catalyst $\mathrm{Cu} / \mathrm{MDPC}-600$ was acquired by heat treatment under nitrogen atmosphere. The catalyst was characterized by X-ray powder diffraction (XRD), $\mathrm{N}_{2}$ physical adsorption (BET), field emission electron microscope (SEM), energy spectrum, and transmission electron microscope (TEM). The results show that the $\mathrm{Cu} / \mathrm{MDPC}-600$ catalyst prepared by using MOF-5 as the template has a very high specific surface area, and Cu is uniformly supported on the carrier. The catalytic hydrogen peroxide oxidation reaction of phenol hydroxylation was investigated and exhibits better catalytic activity and stability in the phenol hydroxylation reaction. The catalytic effect was best when the reaction temperature was $80^{\circ} \mathrm{C}$, the reaction time was $2 \mathrm{~h}$, and the amount of catalyst was $0.05 \mathrm{~g}$. The conversion rate of phenol was $47.6 \%$; the yield and selectivity of catechol were $37.8 \%$ and $79.4 \%$, respectively. The activity of the catalyst changes little after three cycles of use.

\section{Introduction}

Dihydroxybenzene (catechol and hydroquinone) is an important organic intermediate with high value. Among them, catechol is an important organic intermediate for the synthesis of pesticides, medicines, and perfumes. It can also be used to produce dyes, photosensitive materials, electroplating materials, special inks, auxiliaries, and so on. Hydroquinone was mainly used in developer, anthraquinone dyes, azo dyes, synthetic ammonia cosolvents, rubber antioxidants, polymerization inhibitors, stabilizers for coatings and flavors, and antioxidants [1-5]. The production of dihydroxybenzene adopts the green process of direct oxidation of hydrogen peroxide. These reaction conditions were mild, hydrogen peroxide was cheap and easy to obtain, and the oxidation by-product (water) was pollution-free [6]. However, the realization of the hydrogen peroxide oxidation phenol hydroxylation reaction process requires the participation of catalysts, so it is very important to develop an efficient and stable phenol hydroxylation catalyst.
Heterogeneous catalysis has attracted wide attention due to the advantages of easy separation in the process of catalytic reaction. The specific surface area will directly affect the activity of the heterogeneous catalyst. Therefore, the catalytic performance can be improved by increasing the specific surface area and dispersing the catalytic active sites [7]. Porous carbon materials are often used as catalyst supports for heterogeneous catalysis because the surface of carbon materials has acidic, basic, or neutral oxygen-containing groups. These groups interact with catalytic active sites and act as synergistic catalysis [8-10]. Therefore, the catalytic activity of the catalyst can be greatly improved if the specific surface area and porosity of the porous carbon material can be increased.

Metal-organic framework materials (MOFs) are porous materials self-assembled by metal ions and organic ligands. They have a periodic network structure. MOFs were widely used in gas separation, sensing, drug delivery, and heterogeneous catalysis [11-16]. In recent years, it was often used as a template for the preparation of some porous materials 
due to the designability of the structure of MOFs [17-23]. The carbonization of MOFs was particularly interesting. MOFs did not need the other carbons because of their organic ligands. The porous carbon obtained by carbonization of MOFs materials has a huge specific surface area due to the pore size, morphology, and volume of MOFs and can be determined by the selected metal ions and organic ligands. Therefore, the porous carbon from MOFs was a very promising catalyst support material [24-27]. For example, Xiao Ma et al. [28] obtained $\mathrm{N}$-doped porous carbon by one-step pyrolysis of ZIF-67 and then incorporated $\mathrm{Co} / \mathrm{CoO}$ nanoparticles, which have excellent catalytic activity for the tandem dehydrogenation of ammonia borane and the hydrogenation of nitro compounds at room temperature. $\mathrm{Li}$ et al. [29] obtained the $\mathrm{N}$-doped porous carbon (Cz-MOF-253) through rapid pyrolysis of the metal-organic framework material MOF-253, which exhibits excellent catalytic activity in the Knoevenagel condensation reaction. Khan et al. [30] carbonized MOF-5 at $900^{\circ} \mathrm{C}$ and then used the polyol reduction method to prepare PtM/PC900 catalyst, which was used in ethanol fuel cells with a good effect. Wu et al. [31] carbonized and chemically etched $\mathrm{Cu}-\mathrm{MOF}$ to prepare a new three-dimensional matrix containing highly dispersed platinum nanoparticles and amorphous nickel for the first time and prepared two composite catalysts, both exhibition excellent reduction performance of nitrophenol. However, the application of MOFs materials in catalysts is currently limited, and it is still very important to expand new types of MOFs catalysts.

Transition metals were widely used as active sites of catalysts in the phenol hydroxylation reaction. Among them, copper-based catalysts have special attention. Many copper-based catalysts show good catalytic activity for phenol hydroxylation. For example, Wang et al. [32] reported that $\mathrm{Cu}$-substituted mesoporous SBA-15 has excellent catalytic performance and high selectivity to catechol in the hydroxylation of phenol by hydrogen peroxide. At the same time, $\mathrm{Cu}^{2+}$ loaded on zeolites such as $\mathrm{HY}, \mathrm{H} \beta$, USHY, NaY, and HZSM- 5 also showed good catalytic activity for phenol hydroxylation. These catalysts have higher activity than TS-based catalysts [33]. In addition, Cu/MCM-41 [5, 34], Cu/ZSM-5 [35], Cu/HMS [36], and other copper-based catalysts also show good catalytic activity for phenol hydroxylation. Therefore, $\mathrm{Cu}$ is a very potential catalytic active site. In this study, the porous carbon derived from MOFs was used to load copper ions and then subjected to high-temperature heat treatment. The catalyst is a new type of copper-containing porous carbon catalyst that has hardly been reported by previous researchers. The catalyst catalyzes the phenol hydroxylation reaction by hydrogen peroxide, which has good catalytic activity and stability.

\section{Experimental Section}

2.1. Reagents and Chemicals. Zinc nitrate hexahydrate $\left(\mathrm{Zn}\left(\mathrm{NO}_{3}\right)_{2} \cdot 6 \mathrm{H}_{2} \mathrm{O}\right), \mathrm{N}, \mathrm{N}$-dimethylformamide (DMF), ethanol $\left(\mathrm{C}_{2} \mathrm{H}_{6} \mathrm{O}\right.$ ), triethylamine (TEA), polyvinyl pyrrolidone (PVP, k23-27), copper nitrate hexahydrate $\left(\mathrm{Cu}\left(\mathrm{NO}_{3}\right)_{3} \cdot 6 \mathrm{H}_{2} \mathrm{O}\right)$, terephthalic acid $\left(\mathrm{C}_{6} \mathrm{H}_{4}(\mathrm{COOH})_{2}\right)$, hydrochloric acid (36-38\%), hydrogen peroxide $\left(\mathrm{H}_{2} \mathrm{O}_{2}, 30 \%\right)$, phenol $\left(\mathrm{C}_{6} \mathrm{H}_{5} \mathrm{OH}\right)$, ethyl acetate $\left(\mathrm{C}_{4} \mathrm{H}_{8} \mathrm{O}_{2}\right)$, sodium chloride $(\mathrm{NaCl})$, and anhydrous sodium sulfate $\left(\mathrm{Na}_{2} \mathrm{SO}_{4}\right)$ were obtained from Aladdin Industrial Corporation (Shanghai, China). None of the chemicals selected in this work are purified further before use.

\subsection{Preparation of MOF-5. $6.000 \mathrm{~g} \quad \mathrm{Zn}\left(\mathrm{NO}_{3}\right)_{2} \cdot 6 \mathrm{H}_{2} \mathrm{O}$} (6.25 mM), terephthalic acid $(2.8 \mathrm{mM})$, and PVP $(150 \mathrm{mM})$ were poured into a 3-mouth flask; then, $105 \mathrm{~mL}$ DMF and $45 \mathrm{~mL}$ ethanol were added, and a clear solution was obtained after stirring and dissolved. Under stirring intensely, triethylamine $(1 \mathrm{mM})$ was dripped into the solution which gradually became turbid; and then, keeping stirred for $1 \mathrm{~h}$ at $120^{\circ} \mathrm{C}$ before filtered, the filter cake was washed with DMF and ethanol. Finally, after being dried at $100^{\circ} \mathrm{C}, \mathrm{MOF}-5$ was prepared [37].

2.3. Preparation of MDPC-600. Porous carbon was prepared by thermolysis of the previously obtained MOF-5. The white powder of MOF-5 was put into a tube furnace and heated to $600^{\circ} \mathrm{C}$ at a heating rate of $8^{\circ} \mathrm{C} / \mathrm{min}$ with an $\mathrm{N}^{2}$ flow of $150 \mathrm{~mL} / \mathrm{min}$. The MOF-5 powder was maintained at temperature of $600^{\circ} \mathrm{C}$ for 2 hours. Cooling the MOF-5 back down to room temperature, the samples were obtained (designed as sample A). Sample A was subjected to $\mathrm{HCl}$ $(1.1 \mathrm{M})$ washing three times and purified water washing two times to dissolve and remove zinc oxide. The resulting carbon sample was dried in air at $120^{\circ} \mathrm{C}$ overnight (designed as MDPC-600) [38].

2.4. Preparation of $\mathrm{Cu} / \mathrm{MDPC}-600$. Based on $0.5 \mathrm{~g}$ MDPC600 , the required $\mathrm{Cu}\left(\mathrm{NO}_{3}\right)_{2} \cdot 3 \mathrm{H}_{2} \mathrm{O}$ (mass is calculated according to the $\mathrm{Cu}^{2+}$ mass percentage of $1 \%, 2 \%, 3 \%, 4 \%$, and $5 \%$ ) was added to a small beaker containing absolute ethanol (the volume of absolute ethanol is the same as that of $0.5 \mathrm{~g} \mathrm{MDPC}-600)$. After stirring and dissolving at room temperature, add $0.5 \mathrm{~g}$ of MDPC- 600 powder. MDPC-600 powder is completely soaked in ethanol solvent. After being mixed thoroughly, they were dried at $90^{\circ} \mathrm{C}$ for $2 \mathrm{~h}$ to obtain $\mathrm{Cu} / \mathrm{MDPC}-600$ catalysts with $\mathrm{Cu}^{2+}$ mass percentages of $1 \%$, $2 \%, 3 \%, 4 \%$, and $5 \%$, respectively. Then, the obtained $\mathrm{Cu} / \mathrm{MDPC}-600$ catalyst was heated to $600^{\circ} \mathrm{C}$ in a tube furnace under nitrogen atmosphere for heat treatment for $2 \mathrm{~h}$ to obtain the Cu/MDPC-600 catalyst.

2.5. Hydroxylation Reaction of Phenol. Weigh $0.05 \mathrm{~g}$ catalysts of different $\mathrm{Cu}^{2+}$ mass percentages of $1 \%, 2 \%, 3 \%$, and $4 \%$, $0.9 \mathrm{~mL}$ phenol (being heated in the waterbath and dissolved at $\left.50^{\circ} \mathrm{C}\right), 30 \mathrm{~mL}$ deionized water, and $16 \mathrm{~mL}$ hydrogen peroxide solution of mass percentages $30 \%$ and were together added into a round-bottom flask. Under magnetic stirring at $80^{\circ} \mathrm{C}$, the mixture reacted for $2 \mathrm{~h}$. The used catalyst was filtered out, and ethyl acetate was used to extract the product and unreacted phenol from the filtrate three times [39]. The mixture of reactions was analyzed using a gas chromatograph-mass spectrometer (Shimadzu GC-MS-2010 Plus). 
2.6. Characterization of Catalyst. The Brunauer-Emmett-Teller (BET) specific surface areas were measured on the Belsorp-Mini II analyzer (Japan). The catalyst samples were measured using a Rigaku Ultima-IV $\mathrm{XRD}$ system with $\mathrm{Cu}-\mathrm{K} \alpha$ radiation $(\lambda=0.1542 \mathrm{~nm})$. The target voltage and current were $40 \mathrm{kV}$ and $30 \mathrm{~mA}$, respectively. The $2 \theta$ scan range and rate were $5-80^{\circ}$ and $6^{\circ} \mathrm{min}^{-1}$ respectively. The catalyst samples were observed under a ZEISS Sigma HD field emission scanning electron microscopy (FESEM). The accelerating voltage was $8 \mathrm{kV}$. The morphology was observed using the secondary electron detectors in-lens. Meanwhile, the element contents in the samples were analyzed using an Oxford X-Max electric energy spectrum meter (X-MaxN). TEM of the samples was obtained using a JEOL JEM-2010 UHR transmission electron microscope with an accelerating voltage of $200 \mathrm{kV}$. $\mathrm{X}$-ray photoelectron spectroscopy (XPS) was carried out on an RBD upgraded PHI-5000C ESCA system (PerkinElmer) with $\mathrm{MgK}-\alpha$ radiation $(\mathrm{h} \nu=1253.6 \mathrm{eV})$. The contents of $\mathrm{Cu}$ and $\mathrm{Fe}$ in the catalyst were analyzed using inductively coupled plasma (ICP, novAA 300, Analytik Jena AG).

\section{Results and Discussion}

\subsection{Catalyst Structure Characterization}

3.1.1. Sample Analysis by BET. The specific surface area of the catalyst material is an important parameter to measure the catalytic performance. In order to evaluate the influence of the introduction of copper ions on the surface of the catalyst, specific surface area tests were done on MDPC-600 and $\mathrm{Cu} / \mathrm{MDPC}-600$. The $\mathrm{N}_{2}$ adsorption/desorption isotherms of MDPC-600 (Figure 1(a)) and Cu/MDPC-600 (Figure 1(b)) exhibit characteristic IV curves with hysteresis loops. The MDPC-600's specific surface area was $1029.5 \mathrm{~m}^{2} /$ $\mathrm{g}$, the total pore volume was $0.944 \mathrm{~cm}^{3} / \mathrm{g}$, and the average pore diameter was $2.97 \mathrm{~nm}$ (Table 1). But the specific surface area of Cu/MDPC- 600 becomes $824.2 \mathrm{~m}^{2} / \mathrm{g}$ (Table 1). It can be seen that MDPC-600 has a huge specific surface area $\left(1029.5 \mathrm{~m}^{2} / \mathrm{g}\right)$. While the specific surface area of $\mathrm{Cu} / \mathrm{MDPC}-$ 600 drops to $824.2 \mathrm{~m}^{2} / \mathrm{g}$, the loading $\mathrm{Cu}$ occupies part of the pore volume and reduces the porosity. The total pore volume also decreased from $0.944 \mathrm{~cm}^{3} / \mathrm{g}$ to $0.609 \mathrm{~cm}^{3} / \mathrm{g}$, and the average pore diameter decreased from $2.97 \mathrm{~nm}$ to $2.65 \mathrm{~nm}$. However, the $\mathrm{Cu}$ /MDPC-600 loaded with $\mathrm{Cu}$ still has a huge specific surface area which can be beneficial to accelerate the reaction because it can increase the probability of contact between catalyst and reactant.

3.1.2. Sample Analysis by XRD. In order to determine the filling of copper ions in the catalyst material, we performed XRD characterization on the material. Figure 2 shows the XRD patterns of $\mathrm{Cu} / \mathrm{MDPC}-600$. The XRD pattern of $\mathrm{Cu} / \mathrm{MDPC}-600$ matches the form of amorphous porous carbon. However, the characteristic peaks of $\mathrm{Cu}$ with low intensity can be observed on the spectrum at $43.3^{\circ}, 50.5^{\circ}$, and $74.2^{\circ}$. The characteristic peaks of $\mathrm{Cu}$ become more obvious with the increase of $\mathrm{Cu}$ loading because a small number of copper ions are reduced to copper during the carbonization process. The characteristic peaks of other $\mathrm{Cu}$ ions are not obvious because they are dispersed in the porous carbon pores.

3.1.3. Sample Analysis by SEM and TEM. The Figures 3(a) and $3(\mathrm{~b})$ were the morphologies of MOF-5 observed by SEM. It can be seen that MOF-5 is clustered together like petals with a diameter of about $5 \mu \mathrm{m}$. Figures $3(\mathrm{c})$ and $3(\mathrm{~d})$ were the morphologies of the porous carbon MDPC-600, and Figures 3(e) and 3(f) were the morphologies of $\mathrm{Cu} / \mathrm{MDPC}-600$. It can be seen from the figure that the morphology of the porous carbon before and after loading $\mathrm{Cu}$ was unchanged. Both were irregular blocky morphology with a size between $50 \mathrm{~nm}$ and $500 \mathrm{~nm}$, and honeycombshaped pores can be seen on the massive particles. The energy spectrum test of the catalyst with a $\mathrm{Cu}$ content of $3 \%$ is shown in Figure 4. There are three main elements: $\mathrm{C}, \mathrm{O}$, and $\mathrm{Cu}$. It also indirectly verifies that the MOF-5 is carbonized, and then, the $\mathrm{ZnO}$ hydrochloric acid is washed away to obtain porous carbon. It can be seen from Figure 4 that the supported $\mathrm{Cu}$ element distribution is relatively uniform, indicating that $\mathrm{Cu}$ is well dispersed in the catalyst. Figure 5 is a TEM image of the catalyst Cu/MDPC- 600 . From the figure, it can be seen that the catalyst has obvious amorphous characteristics, corresponding to the XRD characterization (Figure 2), and the morphology is irregular.

3.1.4. Sample Analysis by XPS. The XPS spectrum of $\mathrm{Cu} / \mathrm{MDPC}-600$ in Figure 6 shows that $\mathrm{Cu}^{2+}$ is doped into the pores of porous carbon. The XPS wide-scan spectrum in Figure 6(a) shows that the constituent elements of $\mathrm{Cu} / \mathrm{MDPC}-600$ include $\mathrm{C}, \mathrm{O}$, and $\mathrm{Cu}$. Figure $6(\mathrm{~b})$ is the high-resolution XPS spectrum of $\mathrm{Cu} 2 \mathrm{p}$. It can be seen from Figure 6(b) that the peak at $934.7 \mathrm{eV}$ comes from $\mathrm{Cu} 2 \mathrm{p} 3 / 2$, and there is a satellite peak at $943.0 \mathrm{eV}$, indicating the presence of $\mathrm{Cu}^{2+}[40]$ in the material, and the valence state of copper supported in the catalyst is mainly divalent (Figure 6(b)), indicating that $\mathrm{Cu}$ exists in the form of copper oxide during the $\mathrm{Cu}$ loading process.

3.2. Hydroxylation of Phenol. The obtained Cu/MDPC-600 was used to catalyze the phenol hydroxylation reaction, and the supported $\mathrm{Cu}$ mass fractions were $1 \%, 2 \%, 3 \%, 4 \%$, and $5 \%$, respectively. The obtained reaction results are given in Table 2.

Table 2 provides that the yield of hydroquinone increases with the increase of $\mathrm{Cu}$ loading. The best conversion rate of phenol reaches $47.6 \%$ when the $\mathrm{Cu}$ loading was $3 \%$. The yield and selectivity of catechol are $37.8 \%$ and $79.4 \%$, respectively. It shows that $\mathrm{Cu}$ has a good catalytic activity after being heattreated on porous carbon. The yield of hydroquinone begins to decrease when $\mathrm{Cu}$ loading exceeds $3 \%$. That is because the decomposition rate of hydrogen peroxide accelerates when there is increase in $\mathrm{Cu}$ loading. There are other products in the reaction products in addition to hydroquinone, which mainly include tar substances produced by deep oxidation of hydroquinone. From Table 2, it can be seen that the content of other substances increases with the increase of $\mathrm{Cu}$ 


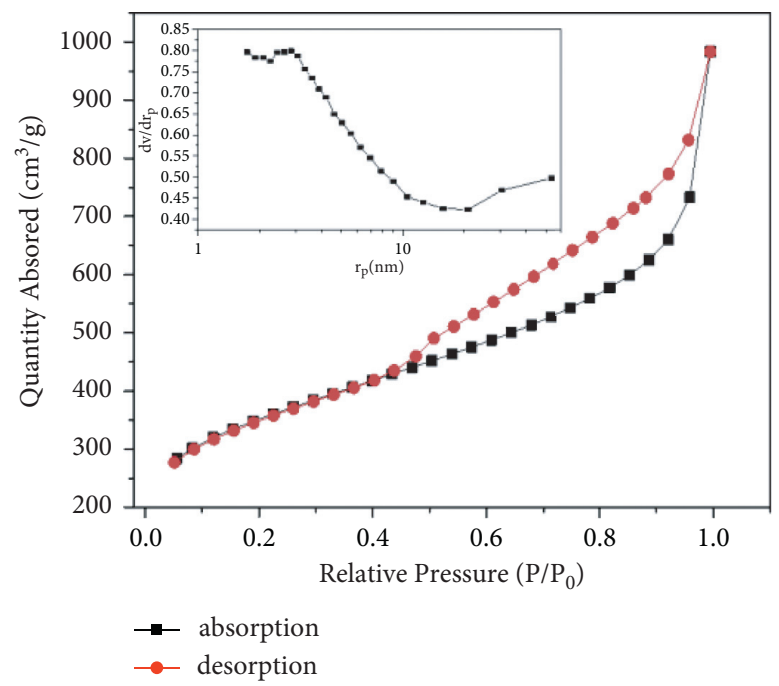

(a)

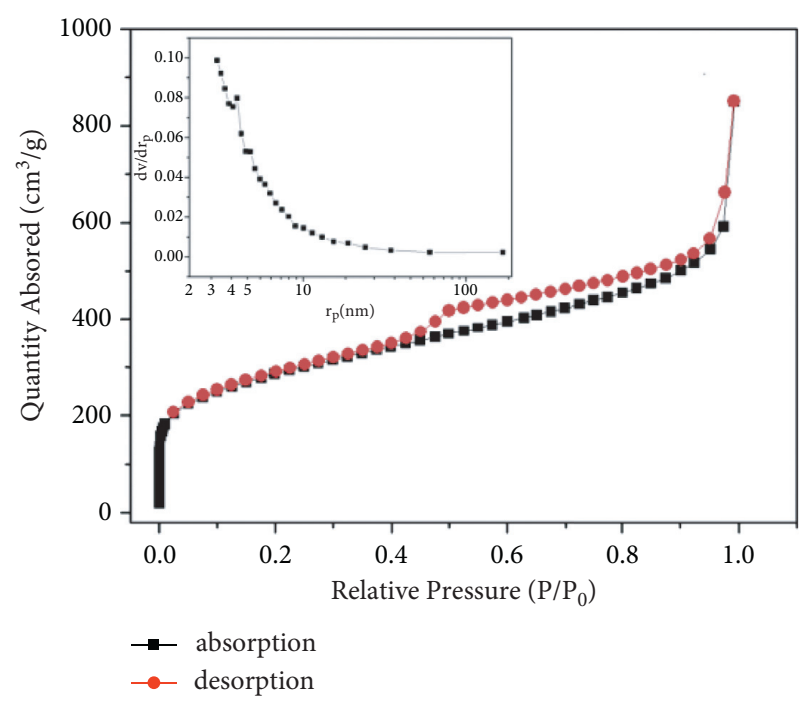

(b)

FIGURE 1: Nitrogen adsorption/desorption isotherm and pore size distribution of the sample. (a) MDPC-600. (b) Cu/MDPC-600.

TABLE 1: DBP absorption value, BET surface area, and pore size of the sample.

\begin{tabular}{lccc}
\hline Sample identification & BET surface area $\left(\mathrm{m}^{2} / \mathrm{g}\right)$ & Pore volume $\left(\mathrm{cm}^{3} / \mathrm{g}\right)$ & Pore diameter $(\mathrm{nm})$ \\
\hline MDPC-600 & 1029.5 & 0.944 & 2.97 \\
Cu/MDPC-600 & 824.2 & 0.609 & 2.65 \\
\hline
\end{tabular}

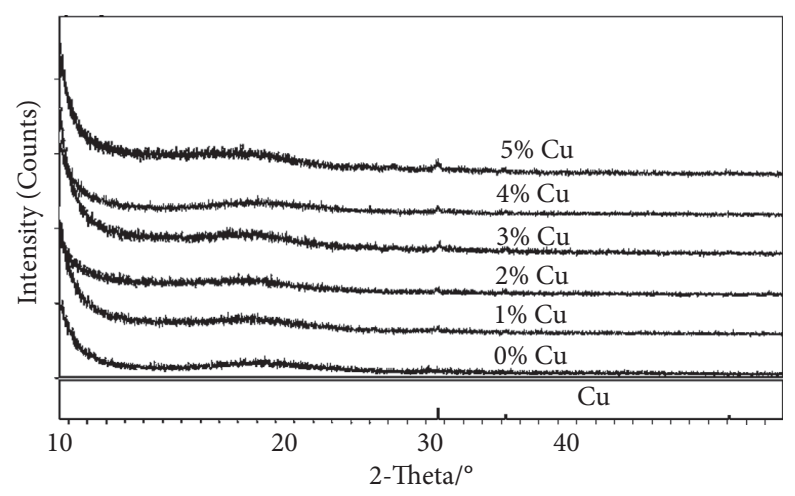

FIGURE 2: XRD analysis of Cu/MDPC-600.

content. Because, the $\mathrm{Cu}$ content increase will accelerate the rate of deep oxidation of the product [41]. Based on the above facts, the optimal catalyst content is considered to be $3 \%$.

Table 3 lists the phenol conversion rate and hydroquinone yield of several other copper-containing catalysts catalyzed by the phenol hydroxylation reaction and compared with the catalyst $\mathrm{Cu} / \mathrm{MDPC}-600$. It is found that the catalyst $\mathrm{Cu} / \mathrm{MDPC}-600$ has a higher phenol conversion rate and hydroquinone selectivity than the catalyst $\mathrm{CuO}-\mathrm{TiO}_{2}$. The phenol conversion rate is slightly lower compared with catalyst Cu-SBA-15 and CuO/Al-SBA-15, but the selectivity of hydroquinone is much higher. Compared with the catalyst $\mathrm{Cu}-\mathrm{SBA}-16$, the selectivity of benzenediol is slightly lower, but the conversion rate of phenol is much higher. It can be seen that the catalyst $\mathrm{Cu} / \mathrm{MDPC}-600$ has relatively good catalytic performance. Compared with the catalyst $\mathrm{Cu} / \mathrm{TS}-1-\mathrm{x}, \mathrm{Cu} / \mathrm{MDPC}-600$ 's phenol conversion rate and hydroquinone selectivity are slightly lower. However, the $\mathrm{Cu} / \mathrm{MDPC}-600$ possessed a simple preparation process and low cost.

3.3. Reaction Mechanism of Phenol Hydroxylation. The catalytic mechanism of phenol oxidation over $\mathrm{Cu}-\mathrm{Fe}-\mathrm{SiO}_{2} / \mathrm{S}$ composite was proposed and is shown in Figure 7, which is similar to a heterogeneous Fenton-like system [46]. In the first step, $\mathrm{Cu}^{2+}$ captures an electron and a hydrogen proton of phenol to form phenoxy radicals. In the second step, phenoxy radicals are further oxidized by hydrogen peroxide to produce o-benzoquinone or p-benzoquinone and a proton and a water molecule. In the third step, o-benzoquinone or p-benzoquinone reacts with the proton to form catechol or 


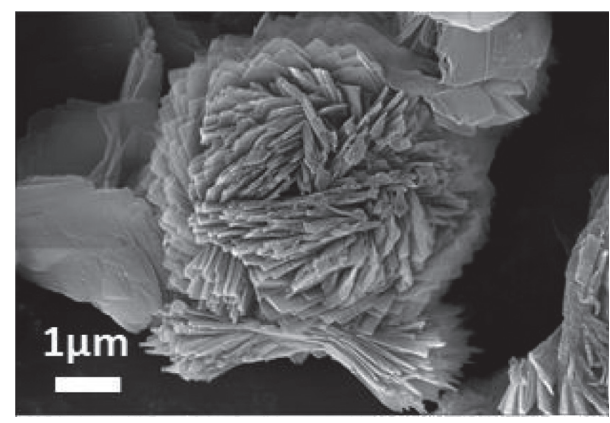

(a)

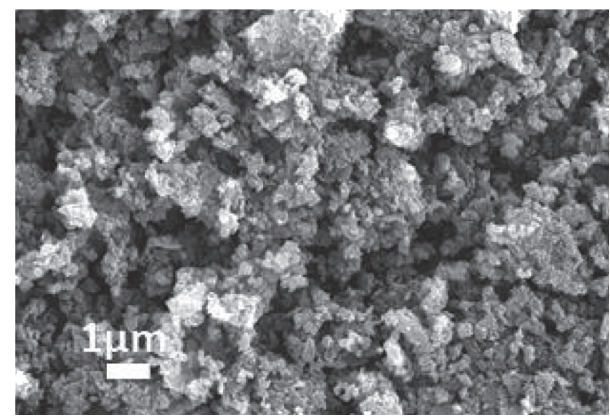

(c)

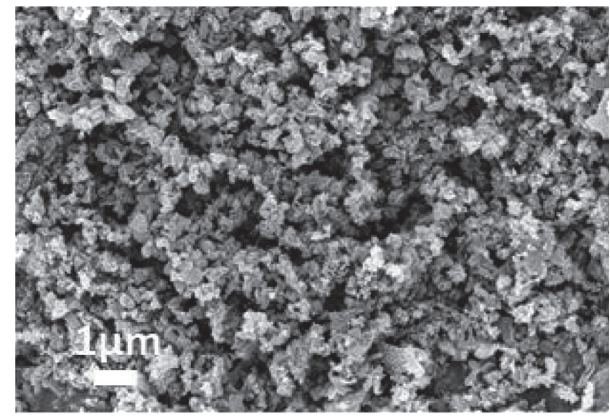

(e)

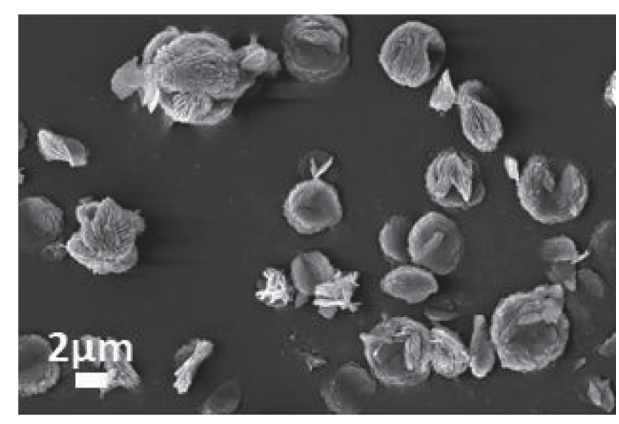

(b)

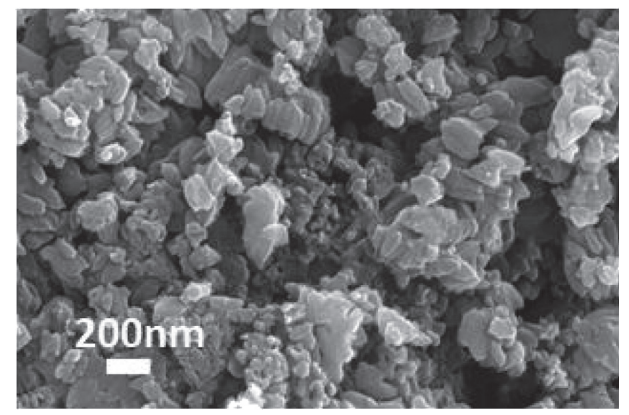

(d)

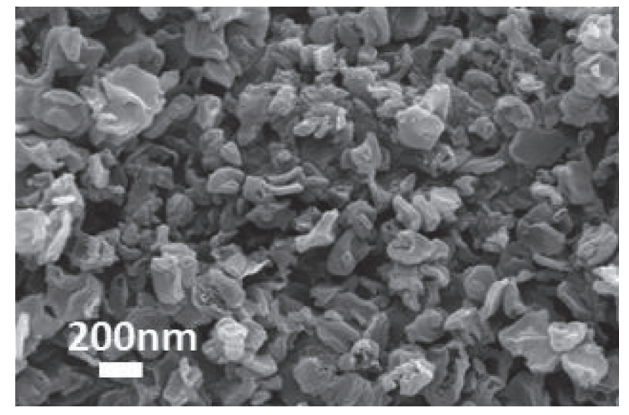

(f)

Figure 3: The SEM images of MOF-5, MDPC-600, and Cu/MDPC-600 (a-b MOF-5; c-d MDPC-600; e-f 3\% Cu/MDPC-60).

hydroquinone [47]. -OH is an ortho or parapositioning group. When the original positioning group on the benzene ring is $-\mathrm{OH}$, the theoretical ratio of ortho to parasubstituent is $73 \%: 27 \%$ [48]. The experimental results show that the catechol selectivity is $65.4-87.8 \%$, not much different from the theoretical. The little difference may be due to the fact that the selection of catalytic active sites greatly influences the selectivity of catalysts in actual reactions [49].

3.4. Influence of Reaction Temperature. The effect of reaction temperature on the hydroxylation of phenol is shown in Figure 8. Reaction conditions: $0.88 \mathrm{~mL}$ phenol, $16 \mathrm{~mL}$ hydrogen peroxide $(30 \%), 30 \mathrm{~mL}$ deionized water, reaction time was $2 \mathrm{~h}$, and catalyst dosage was $0.05 \mathrm{~g}$.

It can be seen that no product was formed at $50^{\circ} \mathrm{C}$ and $60^{\circ} \mathrm{C}$. With the temperature increase, the yield of catechol, phenol conversion, and catechol selectivity all increase above $60^{\circ} \mathrm{C}$. When reaction temperature reached $80^{\circ} \mathrm{C}$, the yield and the selectivity of catechol reached $37.8 \%$ and $79.4 \%$, respectively. Considering the fast decomposition of $\mathrm{H}_{2} \mathrm{O}_{2}$ over $80^{\circ} \mathrm{C}$, the optimal temperature is $80^{\circ} \mathrm{C}$.

3.5. Influence of Reaction Time. The effect of reaction time on the hydroxylation of phenol is shown in Figure 9. Reaction conditions: $0.88 \mathrm{~mL}$ phenol, $16 \mathrm{~mL}$ hydrogen peroxide (30\%), $30 \mathrm{~mL}$ deionized water, reaction time was $2 \mathrm{~h}$, and catalyst dosage was $0.05 \mathrm{~g}$.

It found that the phenol conversion rate and the catechol yield are $31.5 \%$ and $27.8 \%$, respectively, when the reaction time was $0.5 \mathrm{~h}$. The phenol conversion rate and the catechol yield increase slowly with the reaction time becoming longer. This may be because the reaction rate was decreased due to the decrease of $\mathrm{H}_{2} \mathrm{O}_{2}$ concentration in reaction progresses. When the reaction time reach $2 \mathrm{~h}$, the catechol yields were $47.6 \%$ and $37.8 \%$, respectively. The selectivity of catechol decreases from $88.2 \%$ to $79.4 \%$ at the same time. That was because the catechol was deeply 

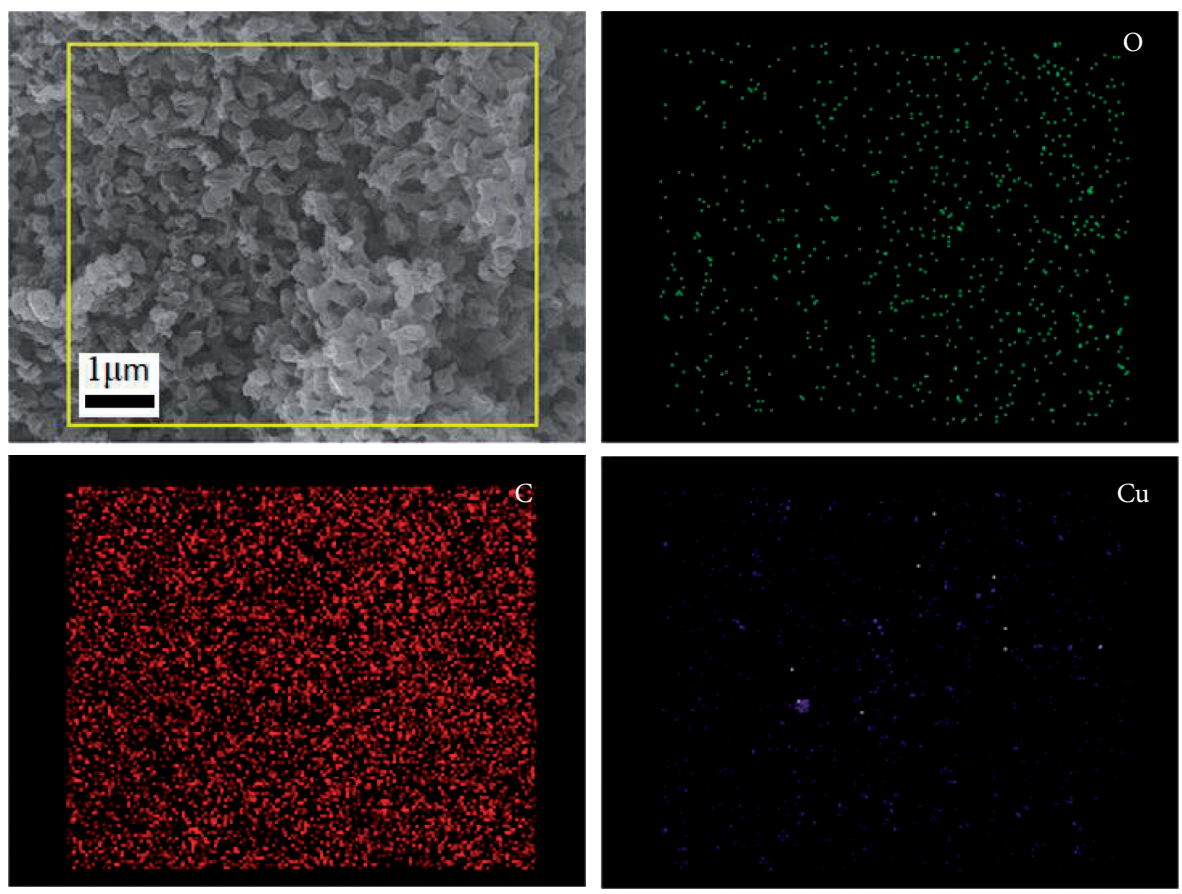

Figure 4: X-MaxN energy spectrum of Cu/MDPC-600 (3\%wt of $\mathrm{Cu}$ ).

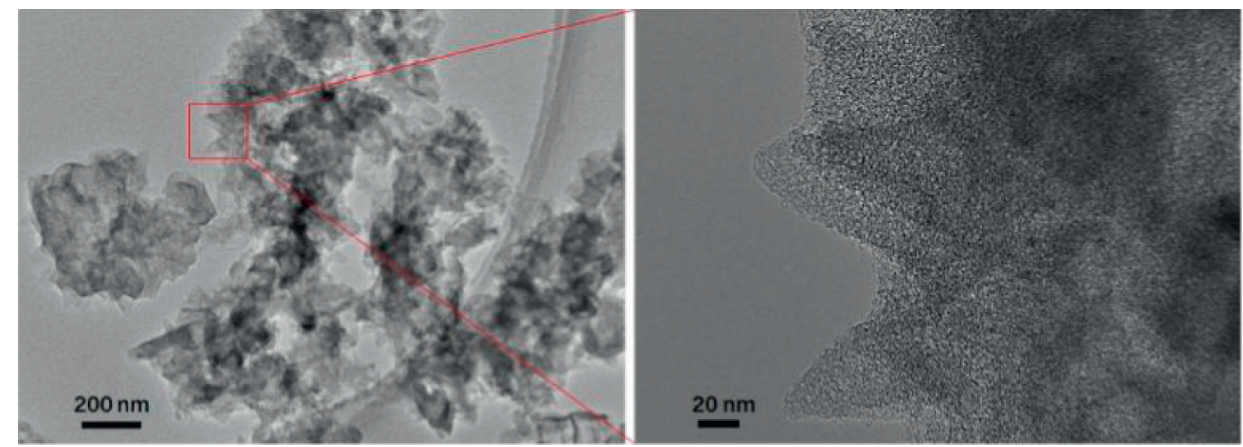

Figure 5: The TEM images of Cu/MDPC-600.

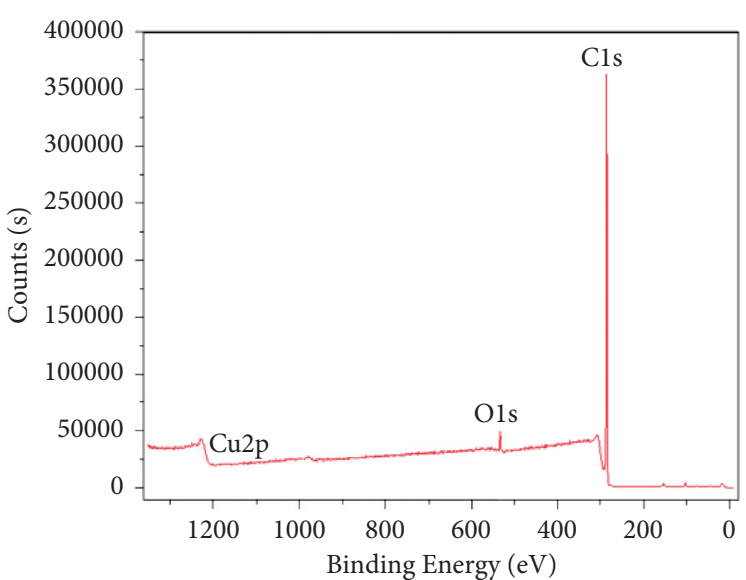

(a)

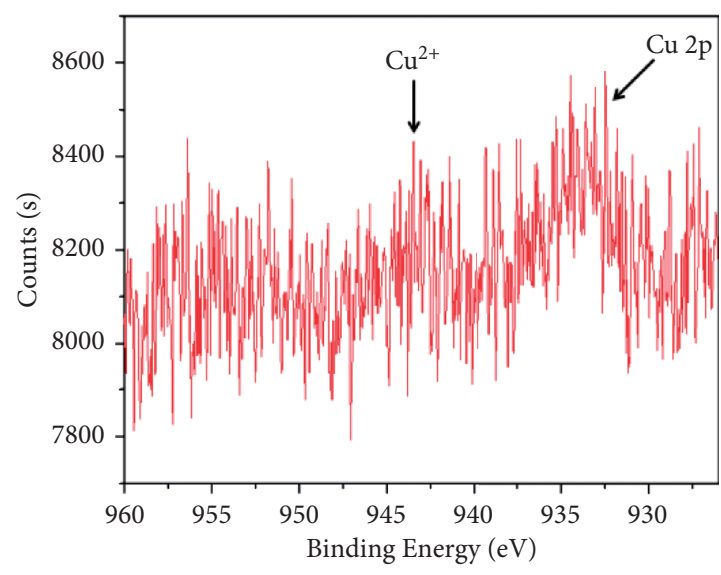

(b)

Figure 6: XPS spectra of Cu/MDPC-600. (a) Wide-scan. (b) Deconvoluted. 
TABLE 2: Catalytic experiment results of phenol hydroxylation.

\begin{tabular}{lcccccc}
\hline Catalyst & $\begin{array}{c}\text { The content of } \mathrm{Cu}^{2+} \\
\text { (mass \%) }\end{array}$ & $\begin{array}{c}\text { Catechol yield } \\
(\%)\end{array}$ & $\begin{array}{c}\text { Hydroquinone yield } \\
(\%)\end{array}$ & $\begin{array}{c}\text { Phenol conversion } \\
\text { rate (\%) }\end{array}$ & $\begin{array}{c}\text { Others } \\
(\%)\end{array}$ & $\begin{array}{c}\text { Catechol selectivity } \\
(\%)\end{array}$ \\
\hline MDPC-600 & 0 & 0 & 0 & 0 & 0 & 0 \\
\hline & 1 & 13.7 & 0 & 15.6 & 1.9 & 87.8 \\
& 2 & 16.7 & 2.1 & 24.6 & 6.8 & 67.9 \\
Cu/MDPC-600 & 3 & 37.8 & 1.4 & 47.6 & 7.4 & 9.4 \\
& 4 & 34.9 & 3.1 & 36.1 & 9.4 & 73.6 \\
\end{tabular}

Reaction conditions: $0.88 \mathrm{~mL}$ phenol, $16 \mathrm{~mL} \mathrm{H}_{2} \mathrm{O}_{2}(30 \%), 30 \mathrm{~mL}$ deionized water, reaction temperature $80^{\circ} \mathrm{C}$, reaction time $2 \mathrm{~h}$, catalyst mass $0.05 \mathrm{~g}$.

TABle 3: Comparative of phenol hydroxylation over $\mathrm{Cu}$-containing catalysts.

\begin{tabular}{lccc}
\hline Catalyst & Phenol conversion rate (\%) & Dihydroxybenzene selectivity (\%) & References \\
\hline $\mathrm{Cu} / \mathrm{TS}-1-\mathrm{x}$ & 49.77 & 99.28 & {$[1]$} \\
$\mathrm{Cu}-\mathrm{SBA}-16$ & 29.4 & 91.5 & {$[42]$} \\
$\mathrm{Cu}-\mathrm{SBA}-15$ & 49.7 & 55.1 & {$[43]$} \\
$\mathrm{CuO}-\mathrm{TiO} 2$ & 25.7 & 81.5 & 68.1 \\
$\mathrm{CuO} / \mathrm{Al}-\mathrm{SBA}-15$ & 64.2 & 82.4 & {$[44]$} \\
$\mathrm{Cu} / \mathrm{MDPC}-600$ & 47.6 & & This study \\
\hline
\end{tabular}

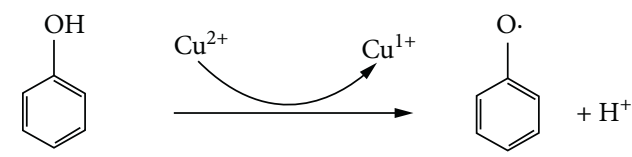

(a)

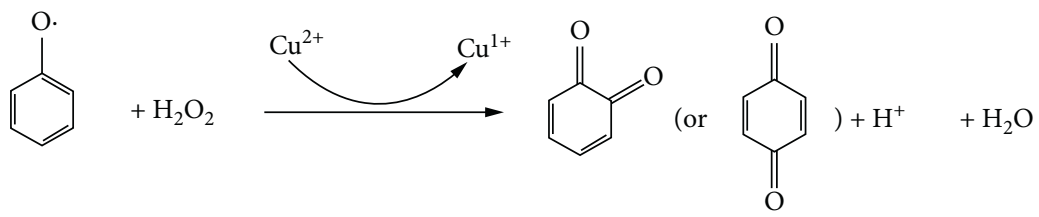

(b)<smiles>O=C1C=CC(=O)C=C1</smiles>

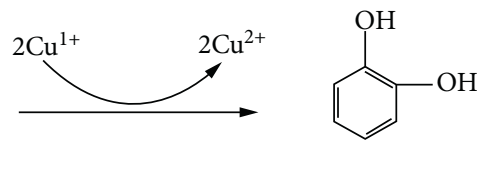

(or<smiles>Oc1ccc(O)cc1</smiles>

(c)

FIgURE 7: Plausible reaction mechanism of phenol hydroxylation.

oxidized leading to the production of other substances that increase, such as tar [50].

3.6. Influence of Catalyst Dosage and Recycling Experiment. The effect of the amount of catalyst on the hydroxylation of phenol is shown in Figure 10. Reaction conditions: $0.88 \mathrm{~mL}$ phenol, $16 \mathrm{~mL}$ hydrogen peroxide $(30 \%), 30 \mathrm{~mL}$ deionized water, reaction temperature was $80^{\circ} \mathrm{C}$, and reaction time was $2 \mathrm{~h}$.

When the amount of catalyst increases, the phenol conversion rate and catechol yield increase first and then decrease, and a slight increase finally. The highest point was the catalyst amount of $0.05 \mathrm{~g}$. The selectivity of catechol decreases with the increase of the amount of catalyst because the increase of the amount of catalyst can promote the reaction. However, the excessive amount of catalyst will cause the excessive decomposition of $\mathrm{H}_{2} \mathrm{O}_{2}$ and the excessive oxidation of products, which is not conducive to the reaction. The increase in the yield of other materials in Figure 9 also confirms this point. Therefore, the optimal amount of the catalyst was $0.05 \mathrm{~g}$.

In order to verify the recyclability of the catalyst, the catalyst was recovered, washed, and dried after the 


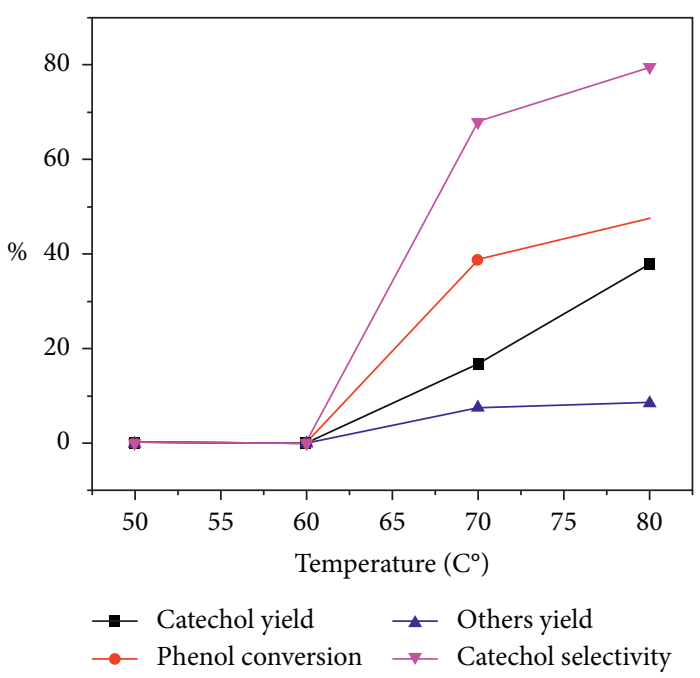

FiguRE 8: Effect of reaction temperature on phenol hydroxylation.

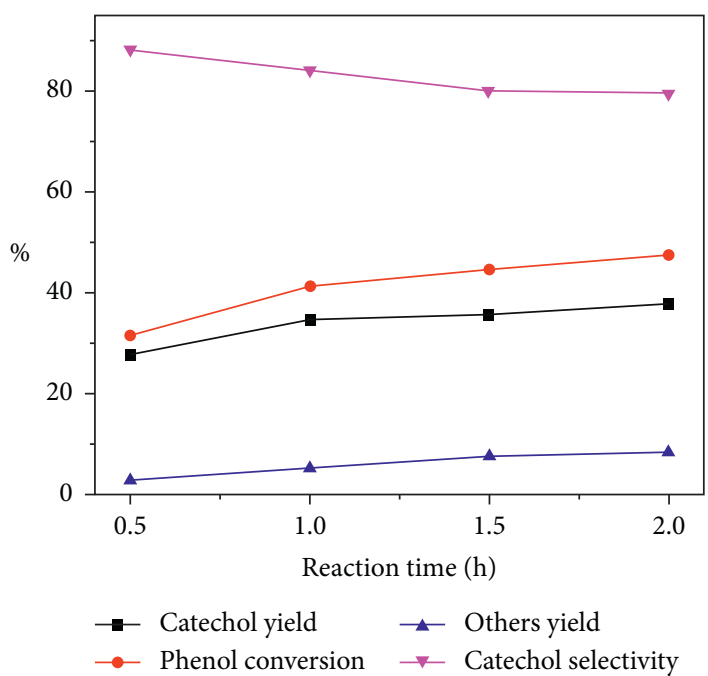

FIgURE 9: Effect of reaction time on phenol hydroxylation.

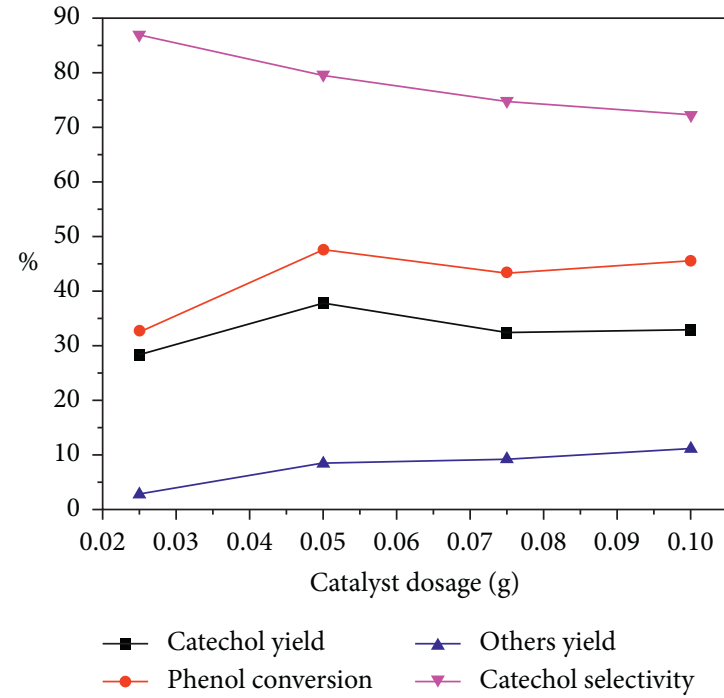

FIgURE 10: Effect of catalyst dosage on the phenol hydroxylation. 
experiment, and then, the phenol hydroxylation reaction was repeated. It was found that the phenol conversion rate and the catechol yield of $\mathrm{Cu} / \mathrm{MDPC}-600$ were $44.4 \%$ and $35.6 \%$, respectively, after being repeated three times. It shows that $\mathrm{Cu} / \mathrm{MDPC}-600$ has higher catalytic activity and repeated use performance in the phenol hydroxylation reaction.

\section{Conclusions}

In this study, the catalyst $\mathrm{Cu} / \mathrm{MDPC}-600$ was obtained by carbonizing MOF-5 at $600^{\circ} \mathrm{C}$ and loading $\mathrm{Cu}$ ions after. The MDPC-600 obtained by carbonizing MOF-5 has a huge surface area of $1029.5 \mathrm{~m}^{2} / \mathrm{g}$, and the specific surface area of the catalyst after loading copper ions was still $824.2 \mathrm{~m}^{2} / \mathrm{g}$. The catalyst has a good catalytic effect in catalyzing the hydroxylation of phenol by hydrogen peroxide because of its huge specific surface area.

In addition, the stability of the combination of copper ions in the catalyst was relatively high due to the heat treatment under nitrogen atmosphere after loading, and the catalyst still has a good catalytic effect after repeated use of the catalyst 3 times.

\section{Data Availability}

The data used to support the findings of this study are included within the article.

\section{Conflicts of Interest}

The authors declare that they have no conflicts of interest.

\section{Acknowledgments}

This study was supported by the scientific research project of Hunan Province Education Department (20C1477), Huaihua Key Laboratory for Preparation of Ceramic Materials and Devices, Special Project of Innovative Provincial Construction in Hunan Province (2020RC1013), the Key Laboratory of Green Catalysis and Reaction Engineering in Hunan High Universities, the Construct Program of the Key Discipline in Huaihua University, Hunan Engineering Laboratory for Preparation Technology of Polyvinyl Alcohol (PVA) Fiber Material (HGY201808), and Research Project of Huaihua University (HHUY2019-17).

\section{References}

[1] G. Wu, J. Xiao, L. Zhang et al., "Copper-modified TS-1 catalyzed hydroxylation of phenol with hydrogen peroxide as the oxidant," RSC Advances, vol. 6, no. 103, pp. 101071-101078, 2016.

[2] B. Li, D. Wang, T. Zhang et al., "High selective hydroxylation of phenol catalyzed by PNP ligand-containing [FeFe]-hydrogenase model complexes," Journal of Chemical Technology and Biotechnology, vol. 95, no. 8, pp. 2180-2186, 2020.

[3] J. Shen, J. Liang, X. Fu et al., "Facile synthesis of CuMgFe layered double hydroxides for efficient catalytic phenol hydroxylation under mild conditions," Chemistry, vol. 5, no. 9, pp. 2835-2841, 2020.
[4] F. Adam, J.-T. Wong, and E.-P. Ng, "Fast catalytic oxidation of phenol over iron modified zeolite L nanocrystals," Chemical Engineering Journal, vol. 214, pp. 63-67, 2013.

[5] Y. Wang, Y. Zhou, M. He, Q. He, and Y. Zhong, "Fe-doped mesoporous alumina: facile one-pot synthesis, modified surface-acidity and its enhanced catalytic performance in phenol hydroxylation," Catalysis Letters, vol. 150, no. 8, pp. 2273-2282, 2020.

[6] E. A. Karakhanov, A. L. Maximov, Y. S. Kardasheva et al., "Hydroxylation of phenol by hydrogen peroxide catalyzed by copper(II) and iron(III) complexes: the structure of the ligand and the selectivity of ortho-hydroxylation," Industrial \& Engineering Chemistry Research, vol. 49, no. 10, pp. 4607-4613, 2010.

[7] D. Schilter, "Heterogeneous catalysis: metastable multipods," Nature Reviews Chemistry, vol. 2, Article ID 0144, 2018.

[8] L. Y. Zhao, X. L. Dong, and A. H. Lu, "Mechanochemical synthesis of porous carbons and their applications in catalysis," ChemPlusChem, vol. 85, no. 5, pp. 866-875, 2020.

[9] C. Zhang, H. Zhao, Z. Li et al., "Rapid access to 3-aminoindazoles from nitriles with hydrazines: a strategy to overcome the basicity barrier imparted by hydrazines," Chemical Communications, vol. 56, no. 66, pp. 9521-9524, 2020.

[10] M. Yao, Y. Ye, H. Chen, and X. Zhang, "Porous carbon supported Pd as catalysts for boosting formic acid dehydrogenation," International Journal of Hydrogen Energy, vol. 45 , no. 35 , pp. 17398-17409, 2020.

[11] M. Fu, Y. Wang, X. Wang, and D. Sun, "Metal-organic framework materials for light hydrocarbon separation," ChemPlusChem, vol. 86, no. 3, pp. 387-395, 2021.

[12] S. Zhang, H. Liu, P. Liu, and D. R. Brown, "Progress of adsorption-based $\mathrm{CO} 2 / \mathrm{CH} 4$ separation by metal organic frameworks," Huagong Xuebao/CIESC Journal, vol. 65, no. 5, pp. 1563-1570, 2014.

[13] M. Gutiérrez, C. Martin, K. Kennes et al., "OLEDs based on metal-organic framework: new OLEDs based on zirconium metal-organic framework (advanced optical materials 6/2018)," Advanced Optical Materials, vol. 6, no. 6, p. 1870022, 2018.

[14] V. F. Samanidou and E. A. Deliyanni, "Metal organic frameworks: synthesis and application," Molecules, vol. 25, no. 4, p. 960, 2020.

[15] S. Gonen and L. Elbaz, "Metal organic frameworks as catalysts for oxygen reduction," Current Opinion in Electrochemistry, vol. 9, pp. 179-188, 2018.

[16] D. N. Dybtsev and K. P. Bryliakov, "Asymmetric catalysis using metal-organic frameworks," Coordination Chemistry Reviews, vol. 437, no. 15, Article ID 213845, 2021.

[17] C.-C. Hou, Q.-Q. Chen, K. Li et al., "Tailoring three-dimensional porous cobalt phosphides templated from bimetallic metal-organic frameworks as precious metal-free catalysts towards the dehydrogenation of ammonia-borane," Journal of Materials Chemistry, vol. 7, no. 14, pp. 8277-8283, 2019.

[18] H.-C. Kim and S. Huh, "Porous carbon-based supercapacitors directly derived from metal-organic frameworks," Materials, vol. 13, no. 18, pp. 4215-2020, 2019.

[19] L. Hu and Q. Chen, "Hollow/porous nanostructures derived from nanoscale metal-organic frameworks towards high performance anodes for lithium-ion batteries," Nanoscale, vol. 6, no. 3, pp. 1236-1257, 2014.

[20] M.-L. Hu, M. Y. Masoomi, and A. Morsali, "Template strategies with MOFs," Coordination Chemistry Reviews, vol. 387, no. 3, pp. 415-435, 2019. 
[21] R. Wu, X. Qian, X. Rui et al., "Zeolitic imidazolate framework 67-derived high symmetric porous Co3O4Hollow dodecahedra with highly enhanced lithium storage capability," Small, vol. 10, no. 10, pp. 1932-1938, 2014.

[22] S. Zhang, H. Liu, C. Sun et al., " $\mathrm{CuO} / \mathrm{Cu} 2 \mathrm{O}$ porous composites: shape and composition controllable fabrication inherited from metal organic frameworks and further application in CO oxidation," Journal of Materials Chemistry, vol. 3, no. 10, pp. 5294-5298, 2015.

[23] H. Yin, X.-X. Yu, Q.-W. Li et al., "Hollow porous $\mathrm{CuO} / \mathrm{C}$ composite microcubes derived from metal-organic framework templates for highly reversible lithium-ion batteries," Journal of Alloys and Compounds, vol. 706, no. 5, pp. 97-102, 2017.

[24] W. Chaikittisilp, M. Hu, H. Wang et al., "Nanoporous carbons through direct carbonization of a zeolitic imidazolate framework for supercapacitor electrodes," Chemical Communications, vol. 48, no. 58, pp. 7259-7261, 2012.

[25] N.-N. Zhang, F. Bigdeli, Q. Miao, M.-L. Hu, and A. Morsali, "Ultrasonic-assisted synthesis, characterization and DNA binding studies of $\mathrm{Ru}(\mathrm{II})$ complexes with the chelating $\mathrm{N}$-donor ligand and preparing of $\mathrm{RuO} 2$ nanoparticles by the easy method of calcination," Journal of Organometallic Chemistry, vol. 878, no. 30, pp. 11-18, 2018.

[26] S. J. Yang, T. Kim, J. H. Im et al., "MOF-derived hierarchically porous carbon with exceptional porosity and hydrogen storage capacity," Chemistry of Materials, vol. 24, no. 3, pp. 464-470, 2012.

[27] Y.-Z. Chen, R. Zhang, L. Jiao, and H.-L. Jiang, "Metal-organic framework-derived porous materials for catalysis," Coordination Chemistry Reviews, vol. 362, pp. 1-23, 2018.

[28] X. Ma, Y.-X. Zhou, H. Liu, Y. Li, and H.-L. Jiang, "A MOFderived Co-CoO@N-doped porous carbon for efficient tandem catalysis: dehydrogenation of ammonia borane and hydrogenation of nitro compounds," Chemical Communications, vol. 52, no. 49, pp. 7719-7722, 2016.

[29] X. Li, B. Zhang, Y. Fang et al., "Metal-organic-frameworkderived carbons: applications as solid-base catalyst and support for Pd nanoparticles in tandem catalysis," Chemistry A European Journal, vol. 23, no. 18, pp. 4266-4270, 2017.

[30] I. A. Khan, A. Badshah, N. Haider, S. Ullah, D. H. Anjum, and M. A. Nadeem, "Porous carbon as electrode material in direct ethanol fuel cells (DEFCs) synthesized by the direct carbonization of MOF-5," Journal of Solid State Electrochemistry, vol. 18, no. 6, pp. 1545-1555, 2014.

[31] X.-Q. Wu, J. Zhao, Y.-P. Wu et al., "Ultrafine Pt nanoparticles and amorphous nickel supported on 3D mesoporous carbon derived from $\mathrm{Cu}$-Metal-Organic framework for efficient methanol oxidation and nitrophenol reduction," ACS Applied Materials \& Interfaces, vol. 10, no. 15, pp. 12740-12749, 2018.

[32] G. Shi, Y. Bao, B. Chen, and J. Xu, "Phenol hydroxylation over cubic/monoclinic mixed phase $\mathrm{CuO}$ nanoparticles prepared by chemical vapor deposition," Reaction Kinetics, Mechanisms and Catalysis, vol. 122, no. 1, pp. 289-303, 2017.

[33] J. Wang, J.-N. Park, H.-C. Jeong et al., "Cu2+-Exchanged zeolites as catalysts for phenol hydroxylation with hydrogen peroxide," Energy \& Fuels, vol. 18, no. 2, pp. 470-476, 2004.

[34] I. Sobczak, M. Ziolek, and M. Renn, "Cu state and behaviour in MCM-41 mesoporous molecular sieves modified with copper during the synthesis-Comparison with copper exchanged materials," Microporous and Mesoporous Materials, vol. 74, no. 1-3, pp. 23-36, 2004.

[35] A. Villa, C. Caro, and C. Correa, "Cu and Fe-ZSM-5 as catalysts for phenol hydroxylation," Journal of Molecular Catalysis
A-chemical-J MOL CATAL A-CHEM, vol. 228, no. 1-2, pp. 233-240, 2005.

[36] Z. Fu, J. Chen, and D. Yin, "Highly effective Cu-HMS catalyst for hydroxylation of phenol," Catalysis Letters, vol. 66, no. 1, pp. 105-108, 2000.

[37] N. Zhao, H. P. Deng, and M. Shu, "Preparation and catalytic performance of Pd catalyst supported on MOF-5," Chinese Journal of Inorganic Chemistry, vol. 26, no. 7, pp. 1213-1217, 2010.

[38] B. 1. Xiang, L. Fu, Y. Li, and Y. Liu, "Two synthesis methods for $\mathrm{Fe}(\mathrm{III}) @ M O F-5$-derived porous carbon composites for enhanced phenol hydroxylation," Chemistry, vol. 4, no. 46, pp. 13638-13645, 2019.

[39] X. W. Xia, "Separation and Purification of catechol," Thesis, Zhenzhou University, Zhenzhou, China, 2007.

[40] Y. Fu, Q. Chen, M. He et al., "Copper ferrite-graphene hybrid: a multifunctional heteroarchitecture for photocatalysis and energy storage," Industrial \& Engineering Chemistry Research, vol. 51, no. 36, pp. 11700-11709, 2012.

[41] X. H. Gao, X. C. Lu, and P. Chen, "Hydroxylation of phenol of phenol with hydrogen peroxide to dihydroxybenzene over Cu/FSM-16," Acta Petrolei Sinica, vol. 28, no. 1, pp. 133-136, 2012.

[42] Y. Dong, X. Niu, Y. Zhu, F. Yuan, and H. Fu, "One-pot synthesis and characterization of Cu-SBA-16 mesoporous molecular sieves as an excellent catalyst for phenol hydroxylation," Catalysis Letters, vol. 141, no. 2, pp. 242-250, 2011.

[43] H. Zhang, C. Tang, Y. Lv et al., "Synthesis, characterization, and catalytic performance of copper-containing SBA-15 in the phenol hydroxylation," Journal of Colloid and Interface Science, vol. 380, no. 1, pp. 16-24, 2012.

[44] T. Yu, S. Zhang, C. Ding, and Z. Zhao, "Study on highly selective hydroxylation of phenol in the aqueous phase," China Chemistry Bulletin, vol. 78, pp. 364-371, 2015.

[45] H. H. Liu, T. L. Jiang, and Y. Q. Wang, "Catalytic performance for hydroxylation of phenol," Chinese Journal of Applied Chemistry, vol. 31, pp. 274-278, 2014.

[46] T. Xu, G. He, Y. Zhao et al., "Benzenoid-like CuFeO2@reduced graphene oxide: facile synthesis and its excellent catalytic performance in selective oxidation," Applied Surface Science, vol. 389, no. 15, pp. 840-848, 2016.

[47] Q. Liu, J. Yu, Z. Wang, P. Yang, and T. Wu, "Preparation, characterization and catalytic properties of alpha - $\mathrm{Fe} 2 \mathrm{O} 3 /$ $\mathrm{SiO} 2$ catalyst in phenol hydroxylation with hydrogen peroxide," Reaction Kinetics and Catalysis Letters, vol. 73, no. 1, pp. 179-186, 2001.

[48] X. F. Zhang, G. M. Zhang, X. D. Chen, and J. C. Zhang, "Phenolic tar formation during products separation of diphenols synthesis by phenol hydroxylation," Spec. Petrochem, vol. 33, no. 11, pp. 26-30, 2004.

[49] L.-G. Qiu, A.-J. Xie, and L.-D. Zhang, "Encapsulation of catalysts in supramolecular porous frameworks: size- and shape-selective catalytic oxidation of phenols," Advanced Materials, vol. 17, no. 6, pp. 689-692, 2005.

[50] T. Zhang, Z. Zhang, J. Zhang, D. Jiang, and Q. Lin, "Preparation of $\mathrm{SiC}$ ceramics by aqueous gelcasting and pressureless sintering," Materials Science and Engineering A, vol. 443, no. 1-2, pp. 257-261, 2007. 